\title{
STUDIES IN INTRAVASCULAR COAGULATION. III. THE PATHOGENESIS OF SERUM-INDUCED VENOUS THROMBOSIS 1,2
}

\section{By STANFORD WESSLER with THE techNicAl ASSISTANCE OF KATHLEEN WARD AND CAROL HO}

\author{
(From the Medical Research Department of the Yamins Research Laboratory, Beth Israel \\ Hospital, and the Department of Medicine, Harvard Medical School, Boston, Mass.)
}

(Submitted for publication October 25, 1954 ; accepted December 8, 1954)

The mechanisms involved in the initiation, propagation, and dissemination of intravascular clots remain obscure. The identification of each new clotting factor has raised the possibility that abnormalities in these factors might be found among patients with thromboembolism. Data have yet to be presented, however, demonstrating a causal relationship between intravascular thrombosis and an alteration in any of these clotting factors. Our efforts to uncover such a relationship proceeded from two observations. One was the impressive evidence that stasis plays an important role in the development of intravascular clotting. The other was the significant fact first established by Alexander, deVries, and Goldstein (1) and later confirmed by Owren (2) and Koller, Loeliger, and Duckert (3) that there is normally present in human serum a stable factor which accelerates prothrombin conversion. This factor has been variously called SPCA, Convertin ${ }^{\circledR}$ and factor VII.

It has been repeatedly stated that blood stagnating in a vein included between two ligatures will remain liquid for weeks $(4,5)$. We have found, however, that although clot formation was never observed in such vein segments of dogs within 20 minutes of their isolation, fibrin clots

1 This study was supported by the Medical Research and Development Board, Office of the Surgeon General, Department of the Army, under contract No. DA-49-007MD-220 and by U. S. Public Health Grant No. H-1027. The work was done, in part, during the tenure of an Established Investigatorship of the American Heart Association.

2 Presented in brief before (a) the Combined Meeting of the Panel on Blood Coagulation of the Subcommittee on Blood and Related Problems, National Research Council, Washington and the Panel on Coagulants and Anticoagulants, Defense Research Board, Ottawa, Canada on April 21, 1954 and (b) the Meeting of the American Society for Clinical Investigation, May 3, 1954. were always recognized in blood completely stagnant in a vein for 90 minutes (6). When first formed, all such clots were small, increased in size only slowly with time and were always incomplete for at least eight hours after isolation of the vein.

\section{METHODS}

To produce large clots rapidly, it was necessary to accelerate coagulation within these isolated vein segments. We selected serum to accomplish this because serum possessed clot promoting activity in vitro, was a natural product of the coagulation process itself, and had, like plasma, been successfully used as a blood substitute in man (7).

It soon became evident that a large thrombus could be regularly induced in the following manner. Dogs, 18 to $23 \mathrm{Kg}$. in weight, were anesthetized with Nembutal A segment of jugular vein three to six $\mathrm{cm}$. in length was freed from its surrounding structures and its tributaries ligated. Canine serum from another animal was then infused into a distant antecubital vein. One minute later, after the infused serum had been dispersed throughout the circulation, the previously freed jugular segment was gently isolated with $27 \mathrm{~mm}$. seraffine clamps. ${ }^{3}$ A large red clot was routinely formed in the isolated vein within 60 seconds after clamping. To produce these clots, volumes of serum in excess of $90 \mathrm{cc}$. and isolation of the vein within two minutes after completion of the serum injection were required.

This technique demonstrated that in the dog the systemic infusion of heterologous canine serum induced a transient hypercoagulable state during which rapid massive thrombosis developed in veins containing stagnant blood far removed from the site of injection. Subsequent experiments have in part characterized the moiety in serum, the degree of stasis and the extent of endothelial damage required to precipitate such intravascular thrombi. In these experiments established methods were used to determine the overall one-stage plasma prothrombic activity (8), prothrombin (9), Ac-globulin (10), and SPCA (11) concentrations.

3 Manufactured by Arthur H. Thomas, Philadelphia, Pa. 


\section{RESULTS}

\section{The clot promoting activity of serum}

Infusions of $100 \mathrm{cc}$. aliquots of physiologic saline solution, and of fresh plasma repeatedly failed to produce venous clots under the same conditions. These findings confirmed the specificity of serum for this reaction and indicated that the effect was not dependent upon a sudden increase in circulating blood volume or clotting factors present only in plasma.

Among the factors necessary for normal coagulation in man," SPCA is found in appreciable amounts in serum stored for 24 hours at $4^{\circ} \mathrm{C}$. Current knowledge does not permit definition of SPCA as one or more distinct substances. For the present, it can be described as an entity which -though distinct from Ac-globulin-is also essential for the physiologic conversion of prothrombin $(12,13)$. SPCA is present in plasma as a precursor called pro-SPCA (pro-convertin). During coagulation pro-SPCA is converted to SPCA (Convertin $\left.{ }^{*}\right)$. The in vitro tests used in this study, however, do not distinguish between the inactive and active forms but measure the total amount of SPCA complex present in a given sample (11). The failure of plasma to induce clotting in isolated venous segments suggests, however, that this phenomenon is not attributable to pro-SPCA but rather to its activated form, SPCA.

To determine the role of SPCA in serum-induced clots, SPCA-poor and SPCA-rich serum and serum fractions were tested. Dicumarol ${ }^{\circ}$ is known to reduce the amount of circulating SPCA complex in addition to prothrombin (14). Serum was therefore obtained from dogs given Dicumarol in which the SPCA content was less than one per cent of the control value. Infusions of $100 \mathrm{cc}$. of such sera repeatedly failed to induce intravascular clotting in stagnant blood. SPCApoor and SPCA-rich serum fractions were obtained by the barium sulfate adsorption of normal canine serum. ${ }^{5}$ Infusions of $100 \mathrm{cc}$. of the super-

These include thromboplastin, antihemophilic globulin (AHG), plasma thromboplastin component (PTC), plasma thromboplastin antecedent (PTA), prothrombin, Ac-globulin, SPCA, thrombin, fibrinogen, and fibrin.

- Barium sulfate (Baker, C.P.) was added to serum previously stored for eight hours at $4^{\circ} \mathrm{C}$. (100 mg. per cc. serum). The mixture was shaken well for five minutes,
TABLE I

Canine SPCA values in serum and corresponding barium sulphate serum eluate (expressed in per cent of normal serum)

\begin{tabular}{cc}
\hline \hline Serum & Baso، eluate \\
\hline 60 & 162 \\
94 & 198 \\
98 & 198 \\
123 & 312 \\
124 & 430 \\
78 & 198 \\
100 & 280 \\
48 & 205 \\
114 & 234 \\
98 & 186 \\
\hline
\end{tabular}

natant of the serum after barium sulfate adsorption, containing only trace amounts of SPCA, failed repeatedly to induce clotting in isolated vein segments. In striking contrast, the dialyzed eluate containing most of the SPCA activity of the parent serum, when infused in $25 \mathrm{cc}$. amounts into a distant antecubital vein, induced a large clot within the segment of jugular vein isolated within 30 seconds of the completion of the injection in 94 of 96 consecutive animals.

Sera after barium sulfate adsorption were rich in SPCA (Convertin ${ }^{\circledR}$ ) activity, having activities two to four times that of the parent serum (Table I). These eluates were free of demonstrable amounts of Ac-globulin and contained at most only trace quantities of thromboplastin, prothrombin, thrombin, fibrinogen and fibrin. Thus, when the eluate was substituted for dog brain thromboplastin in the one-stage prothrombin test, the plasma prothrombin time was 70 seconds instead of 20 , a change representing a $1 / 500$ dilution of thromboplastin. The prothrombin content (twostage) of the preparation was less than one per cent of that in normal canine plasma. The thrombin content of the eluate was negligible: $0.1 \mathrm{cc}$.

allowed to stand at $4^{\circ} \mathrm{C}$. for eight hours, centrifuged at 2,000 rpm. for 20 minutes and the supernatant decanted. The barium sulfate was washed three times with $60 \mathrm{cc}$. $0.02 \mathrm{M}$ acetate buffer ( $\mathrm{pH}$ 4.98). To the washed barium sulfate was added a volume of 5 per cent sodium citrate equal to $1 / 8$ of the original serum volume. This mixture was shaken well and stored for eight hours at $4^{\circ} \mathrm{C}$. The eluate was recovered by centrifugation at $2,000 \mathrm{rpm}$. for 20 minutes and a second elution obtained with a second volume of citrate equal to the first. The combined eluates were dialyzed against running tap water for eight hours. 
mixed with $0.1 \mathrm{cc}$. of either a standard fibrinogen solution or normal dog plasma did not induce a clot in tubes observed for 30 minutes (one unit of thrombin will clot a standard fibrinogen solution in 15 seconds).

Moreover, an infusion of $25 \mathrm{cc}$. of isotonic saline containing 300 to 600 units of bovine thrombin (Parke, Davis) or an infusion containing 25 cc. of a 1 to 10 saline dilution of dog brain thromboplastin ${ }^{\circ}$ were required to induce clots in isolated segments similar to those initiated by $25 \mathrm{cc}$. of the serum after barium sulfate adsorption. Slightly larger amounts of thrombin and thromboplastin produced rapid and extensive intravascular thrombosis frequently killing the animal.

In brief, these observations suggest that the effectiveness of serum in producing intravascular thrombosis may be intimately related to the SPCA activity of the preparation. New factors essential to normal coagulation are, however, still being discovered. Some evidence has been uncovered in our own laboratory indicating that SPCA is not the sole factor responsible for this phenomenon (15).

\section{The role of stasis}

The degree of stasis required to induce a clot was investigated in the following manner. In 14 dogs single silk ties were passed under the right jugular and femoral veins. To reduce trauma, the vessels were not freed from their surrounding structures. The barium sulfate eluate of serum was then infused through an antecubital vein. Within 30 seconds after completion of the infusion the right jugular vein was narrowed ${ }^{7}$ and the right femoral vein occluded by the silk ties. Fifteen minutes later, after the clot-promoting effect of the eluate had been entirely dissipated (15) the left jugular and femoral veins were similarly treated. Examination one hour later revealed that half of the jugular veins which were narrowed and all femoral veins which were occluded within

\footnotetext{
- Thromboplastin extract of dog brain as prepared in the usual manner for one-stage prothrombin determinations.

7 Approximately 75 per cent narrowing of the lumen was accomplished by placing a metal probe ( 0.6 by 2.5 mm.) alongside the vein and tying the ligature snugly around both the probe and vein: the probe was then immediately withdrawn.
}

30 seconds after the injection contained large nonadherent thrombi distal to the sites of obstruction. In none of the veins narrowed or occluded $15 \mathrm{~min}$ utes after the injection was a single clot found. The evidence clearly indicates that whereas local stasis alone was uniformly inadequate to induce thrombosis, the combination of local stasis and systemically infused SPCA-rich serum fractions promptly triggered clot formation at these sites of local obstruction. Moreover, stasis did not have to be complete, although complete obstruction increased the incidence and size of the clot.

\section{Role of endothelial damage}

The extent to which endothelial injury may contribute to this experimental induction of intravascular thrombosis is difficult to evaluate. From the above and from earlier observations (16) it is clear that narrowing per se does not produce enough endothelial damage to induce thrombosis by the method used. Moreover, histologic study of vein segments examined one to 43 days after venous narrowing showed no evidence of intimal damage or superimposed thrombosis. Such histologic observations, of course, do not exclude morphologic injury (17). The absence of significant endothelial injury was further suggested, however, by the repeated observation that clots arrested at such narrowed areas did not become adherent to the underlying vein wall until after the fourth day (16). Finally, in a series of 16 dogs the jugular veins were obstructed by gentle manual pressure or by tourniquets inflated to a pressure of $40 \mathrm{~mm}$. of mercury immediately after the infusion of the serum eluate. Although in none of these animals were the veins isolated or the skin incised until after the effect of the infusion had been dissipated, grossly visible thrombi were demonstrated distal to the obstructed zone in half of the animals.

\section{DISCUSSION}

In man it has been suggested that SPCA may play a role in thromboembolism $(14,18)$. Several investigators have, in fact, demonstrated a temporary rise in the SPCA complex of human pregnant and post-partum plasma (19-22). No correlation has yet been made, however, between 
these increased levels of circulating SPCA complex and the occurrence of thromboembolism.

The studies herein described provide the first direct experimental evidence that, in the dog, the infusion of canine serum or serum fractions rich in SPCA may initiate venous thrombosis at sites of partial or complete stasis. Significant endothelial reaction has not been implicated as a factor in this reaction, and in any event is similar in all control situations where thrombi do not occur. It is well known that retarded local venous flow and the production of serum are common to the postoperative and post-partum states. It is therefore proposed as a working hypothesis that the pathogenesis of venous thrombosis in these clinical conditions may be referable to local venous stasis combined with a transient increase in SPCA activity or in some other entity produced during coagulation, present in serum and exhibiting the characteristics already described. Further purification of pro-SPCA and SPCA and improved methods for their specific measurement will aid in determining the validity of the proposition.

In addition to affording some insight into a mechanism whereby intravascular thrombosis may actually be induced in man, the technique herein described provides a new experimental approach to the multifaceted problems of thromboembolism. In the laboratory it has already afforded a unique method for comparing the efficacy of various anticoagulant and lytic agents recommended in the treatment of thromboembolism $(23,24)$. The method has also provided an additional tool for the in vivo investigation of venous thrombosis and pulmonary embolism.

\section{SUM MARY}

The technique herein described provides a new experimental tool for the investigation of many problems in the field of thromboembolism. The systemic infusion of canine serum or its $\mathrm{BaSO}_{4}$ eluate produces, in the dog, massive intravascular thrombosis at localized sites of retarded or obstructed venous flow. Significant endothelial injury need not be involved in this reaction. It is proposed that the pathogenesis of venous thrombosis in the postoperative and post-partum states may be referable to a transient increase in SPCA activity or some other as yet unidentified entity in serum together with local venous stasis.

\section{REFERENCES}

1. Alexander, B., deVries, A., and Goldstein, R., A prothrombin activator in serum, and its significance in certain hemorrhagic diseases. J. Clin. Invest., 1948, 27, 523.

2. Owren, P. A., The prothrombin activating complex and its clinical significance. In Proc. 3rd Internat. Cong. Internat. Soc. Hemat., New York, Grune and Stratton, 1951, p. 379.

3. Koller, F., Loeliger, A., and Duckert, F., Experiments on a new clotting factor (Factor VII). Acta haematologica, 1951, 6, 1.

4. Glénard, F., Contribution à L'Etude des Causes de la Coagulation Spontanée du Sang à Son Issue de L'Organisme; application à la transfusion. Paris Theses nos. 50, 1875.

5. Baumgarten, P., Die Sogenannte Organisation des Thrombus. Leipzig, Otto Wigand, 1877.

6. Wessler, S., Studies in intravascular coagulation. I. Coagulation changes in isolated venous segments. J. Clin. Invest., 1952, 31, 1011.

7. Mudd, S., and Thalhimer, W., eds., Blood Substitutes and Blood Transfusion. Springfield, IIl., Charles C Thomas, 1942.

8. Rosenfield, R. E., and Tuft, H. S., Estimation of prothrombin level from prothrombin time. Am. J. Clin. Path., 1947, 17, 405.

9. Ware, A. G., and Seegers, W. H., Two-stage procedure for the quantitative determination of prothrombin concentration. Am. J. Clin. Path., 1949, 19, 471.

10. Alexander, B., Goldstein, R., and Landwehr, G., The labile factor of prothrombin conversion: its consumption under normal and pathological conditions affecting blood coagulation. J. Clin. Invest., 1951, 30, 252.

11. Alexander, B., Determination of SPCA in Tocantins, L. M., The Coagulation of Blood. Methods of Study, New York, Grune and Stratton, 1955, p. 144-6.

12. Alexander, B., Ac-Globuline et SPCA : deux facteurs plasmatiques de la conversion de la prothrombine. Etude et revue cliniques et biologiques. Rev. d'hémat., 1952, 7, 168.

13. Owren, P. A., New clotting factors in Trans. 5th Conf. Blood Clotting and Allied Problems, New York, Josiah Macy, Jr. Foundation, 1952, p. 92.

14. Alexander, B., deVries, A., and Goldstein, R., A factor in serum which accelerates the conversion of prothrombin to thrombin. II. Its evolution with special reference to the influence of conditions which affect blood coagulation. Blood, 1949, 4, 739.

15. Wessler, S., Unpublished data. 
16. Wessler, S., Experimental intravascular thrombosis induced by serum fractions containing serum prothrombin conversion accelerator (SPCA). Federation Proc., 1953, 12, 152.

17. Samuels, P. B., The relation of venous endothelium to thrombosis. Report of Annual Meeting and Proceedings, Royal College of Physicians and Surgeons of Canada, 1953, p. 75.

18. de Nicola, P., Factor VII (SPCA): its physiopathologic significance. Blood, 1953, 8, 947.

19. Loeliger, A., and Koller, F., Behaviour of factor VII and prothrombin in late pregnancy and in the newborn. Acta haematologica, 1952, 7, 157.

20. Larrieu, M. J., Soulier, J. P., and Minkowski, A., Le Sang du cordon ombilical : étude complète de sa coagulabilité, comparaison avec le sang maternel. Etudes Néo-Natales, 1952, 1, 39.
21. Alexander, B., Meyers, L., Goldstein, R., Gurewich, V., and Grinspoon, L., Elevated SPCA (convertin) complex in pregnancy. Its possible role in pathogenesis of thromboembolism. J. Clin. Invest., 1954, 33, 914.

22. Creveld, S., van Paulssen, M. M. P., Ens, J. C., Meij, C. A. M. van der, Versteeg, P., and Versteegh, E. T. B., Proconvertin content in the blood of newborn full-term and premature infants. Neonatal Studies, 1954, 3, 53.

23. Wessler, S., Studies in intravascular coagulation. II. A comparison of the effect of Dicumarol and heparin on clot formation in isolated venous segments. J. Clin. Invest., 1953, 32, 650.

24. Wessler, S., Experimentally produced phlebothrombosis in the study of thromboembolism. J. Clin. Invest., 1953, 32, 610. 